\title{
Hepatocellular carcinoma in Yemeni patients: a single centre experience over an 8-year period
}

\author{
A.K. Salem, ${ }^{1}$ A. Abdulrab, ${ }^{2}$ Y. Alfakeh ${ }^{2}$ and A. Aown ${ }^{2}$
}

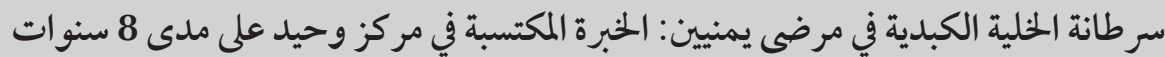

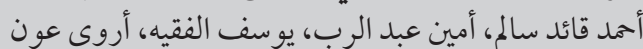

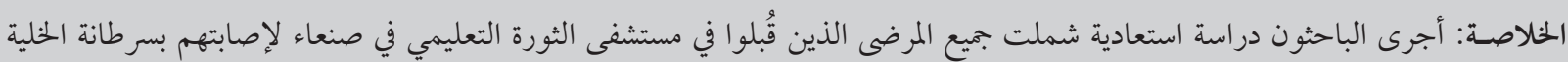

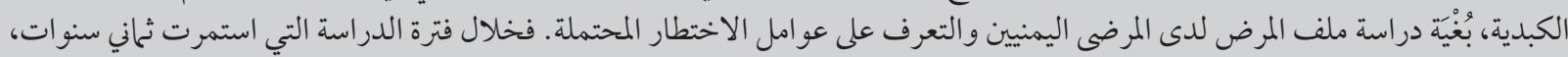

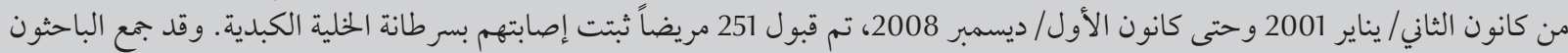

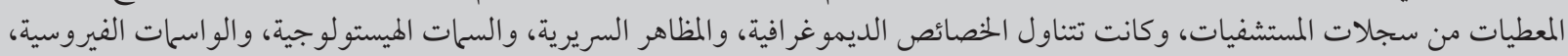

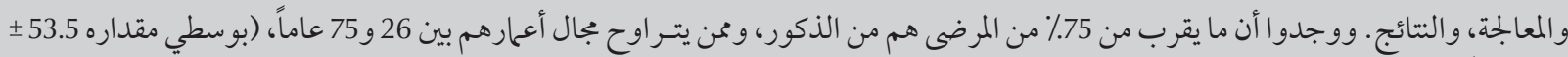

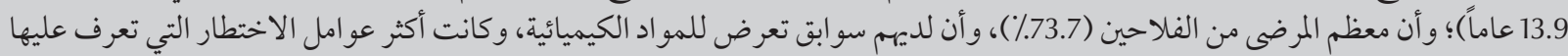

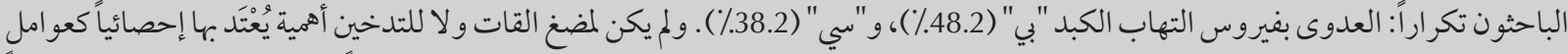

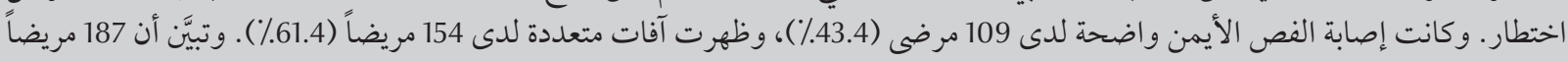

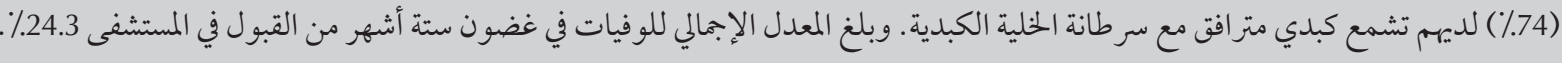

ABSTRACT We carried out a retrospective study of all patients admitted to Al-Thawra Teaching Hospital in Sana'a with hepatocellular carcinoma to study the disease profile in Yemeni patients and identify possible risk factors. During the 8-year study period, January 2001-December 2008, 251 patients were admitted with confirmed hepatocellular carcinoma. From hospital records we collected data on demographic characteristics, clinical manifestations, histological characters, viral markers, treatment and outcome. Around $75 \%$ of the patients were males. Age range was 26-75 years, mean 53.5 (SD 13.9) years. Most patients were farmers (73.7\%) and had a history of chemical contact. Chronic hepatitis B virus infection (48.2 \%) and hepatitis C virus infection (38.2\%) were the most frequently identified risk factors. Qat chewing and smoking were not statistically significant risk factors. Right lobe involvement was seen in 109 (43.4\%) patients and 154 (61.4\%) presented with multiple lesions. We found 187 (74.0\%) patients had cirrhotic liver associated with hepatocellular carcinoma. Overall mortality rate within 6 months of admission to hospital was $24.3 \%$.

\section{Carcinome hépatocellulaire chez des patients yéménites : étude monocentrique sur huit ans}

RÉSUMÉ Nous avons mené une étude rétrospective de tous les dossiers des patients admis au centre hospitalier universitaire Al-Thawra de Sanaa pour un carcinome hépatocellulaire, afin d'identifier le profil pathologique chez des patients yéménites et les facteurs de risque possibles. Pendant les huit années de l'étude, de janvier 2001 à décembre 2008, 251 patients ont été admis pour un carcinome hépatocellulaire confirmé. Nous avons recueilli des données sur les caractéristiques démographiques et histologiques, les manifestations cliniques, les marqueurs viraux, les traitements et les résultats. Environ $75 \%$ des patients étaient de sexe masculin. L'âge des patients allait de 26 ans à 75 ans. L'âge moyen était de 53,5 ans (E.T. 13,9). La plupart des patients étaient agriculteurs $(73,7 \%)$ et avaient des antécédents de contact avec des produits chimiques. Les facteurs de risque les plus fréquemment identifiés étaient une infection chronique par les virus de l'hépatite B (48,2\%) et de l'hépatite C (38,2\%). La mastication de khat et le tabagisme n'étaient pas des facteur de risque statistiquement importants. Le lobe droit était atteint chez 109 patients (43,4\%), et 154 d'entre eux (61,4\%) présentaient des lésions multiples. Nous avons observé que 187 patients $(74,0 \%$ ) souffraient d'un foie cirrhotique concomitant d'un carcinome hépatocellulaire. Le taux de mortalité global à six mois de l'admission à l'hôpital était de 24,3 \%.

'Department of Medicine, Faculty of Medicine and Health Sciences, Sana'a University, Sana'a, Yemen (Correspondence to A. K. Salem: drahmedkaeed@yahoo.com). 2Medical Department, Faculty of Medicine and Health Sciences, Al-Thawra Teaching Hospital, Sana'a, Yemen. Received: 10/08/10; accepted: 31/10/10 


\section{Introduction}

Hepatocellular carcinoma (HCC) is the third most common cause of cancer mortality in the world. It accounts for over half a million deaths per year [1]. More than $80 \%$ of these occur in the developing countries [1]. The incidence rate of liver cancer varies widely from 52.1 per 100000 population in China to 5.1 per 100000 population in Northern Europe, depending on the geographical location and to exposure to viral etiology [1]. In the Middle East HCC is reported to account for about $4.7 \%-7.3 \%$ of patients with chronic liver disease. [2]. A report from Yemen indicated that hepatocellular carcinoma was the most common gastrointestinal tumour, representing $38.66 \%$ of all gastrointestinal malignancy [3].

The epidemiology of HCC is characterized by marked demographic and geographic variations. There are great regional differences in the pathology and epidemiology. The variation is greatly influenced by the etiology of the disease. [4]. The main recognized risk factors for HCC development are aflatoxin $\mathrm{B} 1$ ingestion and chronic viral hepatitis $\mathrm{B}$ and $\mathrm{C}$ infection; these are associated with over $80 \%$ of HCC worldwide [4]. Schistosomiasis, a regional risk factor, has not proven to be a risk factor for HCC development [5]. Exposure to exogenous chemicals, such as insecticides, pesticides and chlorination byproducts in drinking water, have been reported to be fundamental sources for hepatocarcinogenesis [6].

In a 2006 study, HCC developed in $70 \%-90 \%$ of cirrhotic patients, while only $10 \%$ of HCC patients have a noncirrhotic liver, nor even have inflammatory lesions [7]. Epidemiologic data from neighbouring countries differ widely with regard to primary risk factors. It has been attributed to hepatitis $\mathrm{C}$ virus $(\mathrm{HCV})$ infection in Saudi Arabia $[8,9]$, hepatitis B virus/hepatitis D virus (HBV/HDV) infection in Jordan [10] and HBV and HCV in Turkey $[11,12]$.
Studies on HCC in Yemen are few, and are not documented in the local or international literature. This study is the first comprehensive study to elucidate HCC in Yemen. Our aim was to determine the profile of hepatocellular carcinoma in Yemeni patients and to identify possible risk factors.

\section{Methods}

The study was conducted at Al-Thawra Teaching Hospital, a teaching and referral hospital providing special care for patients from the whole of Yemen. Over a period of 8 years, January 2001-December 2008 , a total of 435 patients were admitted into hospital with suspicion of HCC on a clinical basis. Only 251 of these fulfilled the inclusion criteria, any 1 of: abnormal liver morphology with a tumour nodule on ultrasonography or on computer tomography (CT) scan or magnetic resonance imaging (MRI); elevated $\alpha$-fetoprotein level (> $400 \mathrm{ng}$ / $\mathrm{mL}$ ) in the presence of a liver nodule; biopsy-proven HCC.

Data about patients were collected from hospital records, reviewed and organized according to the following:

- sociodemographic characteristics including: age, sex, occupation, residence (urban or rural), specific habits (e.g. use of qat or shama);

- history of exposure to risk factors of viral hepatitis such as blood transfusion, schistosomiasis and personal habits;

- clinical data: symptoms, and signs, diagnostic tools and clinical staging;

- laboratory findings: haematological status, liver function tests, renal function tests;

- radiological data: site of the tumour, multiplicity of lesions, tumour burden, abdominal metastases by abdominal ultrasound and/or CT scan and chest metastases by chest $\mathrm{X}$-ray;

- pathological data: tumour grading, histological classification, tumour markers and association of liver cirrhosis;

- pattern of serological markers: a-fetoprotein level, schistosomiasis serology, hepatitis B surface antigen (HBsAg), and $\mathrm{HCV}$ antibodies (HCV-Ab);

- mortality while hospitalized (hospital stay ranged from 1 week to 6 months. HCV-Ab was detected using second generation ELISA (Boehringer Mannheim Immunodiagnostics for ES-300). HBsAg was confirmed by ELISA test (Abbot Laboratories), and a-fetoprotein level was tested using the method of Abbot Laboratories.

Diagnosis of HCC was based on histopathological examination and/or detection of hepatic focal lesions by 2 imaging techniques (ultrasonography and dynamic CT) plus $\alpha$-fetoprotein level $\geq 200 \mathrm{ng} / \mathrm{mL}$.

\section{Statistical data}

All data were statistically analysed using SPSS, version 13 . We used the $\chi^{2}$ test to detect significant associations between proportions. A univariate model was used to determine the impact of the various risk factors on HCC. The independent factors were age, sex, history of blood transfusion, schistosomiasis, HCV-Ab, HBsAg positivity, occupation and personal habits. A $P$-value of $<0.05$ was considered to indicate statistical significance.

\section{Results}

During the 8 years covered by our study, 251 patients were admitted to the hospital and confirmed as having HCC. Cirrhosis coexisted with HCC in 187 patients, 64 patients were coded as non-cirrhotic HCC. The majority of the patients (189) were males (75.3\%) (Table 1), giving a male to female ratio of 3.05:1. $\left(\chi^{2}=24, P=0.001\right)$.

Table 1 shows the characteristic of patients with HCC. Age ranged from 26 


\begin{tabular}{|c|c|c|}
\hline Characteristic & No. & $\%$ \\
\hline \multicolumn{3}{|l|}{ Age (years) } \\
\hline $21-40$ & 45 & 17.3 \\
\hline $41-60$ & 123 & 49.0 \\
\hline $61-80$ & 83 & 33.1 \\
\hline \multicolumn{3}{|l|}{ Sex } \\
\hline Male & 189 & 75.3 \\
\hline Female & 63 & 24.7 \\
\hline \multicolumn{3}{|l|}{ Residence } \\
\hline Rural & 200 & 79.7 \\
\hline Urban & 51 & 20.3 \\
\hline \multicolumn{3}{|l|}{ Occupation } \\
\hline Farmer & 185 & 73.7 \\
\hline Builder & 31 & 12.3 \\
\hline Housewife & 20 & 8.0 \\
\hline Other & 15 & 6.0 \\
\hline \multicolumn{3}{|l|}{ Habit $^{a}$} \\
\hline Qat chewing & 231 & 92.0 \\
\hline Smoking & 189 & 75.3 \\
\hline Tobacco chewing (shama) & 95 & 21.9 \\
\hline \multicolumn{3}{|l|}{ Riskfactor } \\
\hline Blood transfusion & 30 & 12.0 \\
\hline Hepatitis B infection & 121 & 48.2 \\
\hline Hepatitis C infection & 96 & 38.2 \\
\hline Schistosomiasis & 88 & 35.0 \\
\hline Dual infection ${ }^{b}$ & 6 & 2.4 \\
\hline$\alpha$-fetoprotein $(>200 \mathrm{ng} / \mathrm{mL})$ & 112 & 44.6 \\
\hline
\end{tabular}

${ }^{a}$ Each patient had $\geq 2$ habits.

${ }^{b}$ Dual infection: hepatitis $B+$ hepatitis $C$.

to 75 years with a mean of 53.5 [standard deviation (SD) 13.9] years. Almost half the patients were aged $41-60$ years. The majority of the patients 203 (80.9\%) came from rural areas. The patients were grouped according to their occupation into 4 groups as shown in Table 1. It is clear that most cases 185 (73.7\%) were farmers who gave a history of chemical contact (insecticides/pesticides/fertilizers), only 66 (26.3\%) patients were not farmers.

\section{Clinical finding in patients}

The majority of patients (98\%) presented with frequent abdominal pain, followed by hepatomegaly (94\%) and biopsy in 35 (16.1\%) and fine needle aspiration in 29 (13.3\%). However, in $34(13.6 \%)$ patients the diagnosis was established by high serum $\alpha$-fetoprotein besides the malignant character of the tumour via ultrasonography, CT scan or MRI.

Histopathological types found in our cases were trebecular (47.2\%), mixed $(22.12 \%)$, acinar (11.52\%), pseudopapillar (10.6\%) and fibrolamel$\operatorname{lar}(9.22 \%)$.

\section{Risk factors and personal habits}

The risk factors and personal habits of our patients with HCC are illustrated in Tables 1 and 4. Most of our patients 217 had hepatitis virus infection. Virus markers were negative in only $13.5 \%$ of the patients and this was more obvious in non-cirrhotic cases. HBsAg positive cases accounted for 121 (48.2\%) cases and 96 (38.2\%) were HCV Ab positive. HCV-Ab-positive cases were at double risk, while HBsAg had almost triple the risk of developing HCC. Double infection (HBsAg and HCV Ab) was found in only 6 patients. Occupation (being a farmer) was also significantly associated with HCC $(P=0.01)$ (Table 4).

Residents of rural areas, patients with previous history of schistosomiasis and/or blood transfusion were not significantly associated with HCC in the univariate analysis (Table 4).

Qat chewers accounted for $92.0 \%$ of the patients and smokers $75.3 \%$. Chewing tobacco (shama user) was reported in 21.9\%; only a few patients reported that they consumed alcohol and only in small amounts. Schistosoma serology was positive in 91 (36.2\%) patients. There was no statistically significant difference between cirrhotic and noncirrhotic patients with HCC regarding the above risk factors (Table 4). Serum a-fetoprotein level was greater than $200 \mathrm{ng} / \mathrm{mL}$ in $44.6 \%$ of the patients.

The patients with HCC who did not have cirrhosis were younger than those 


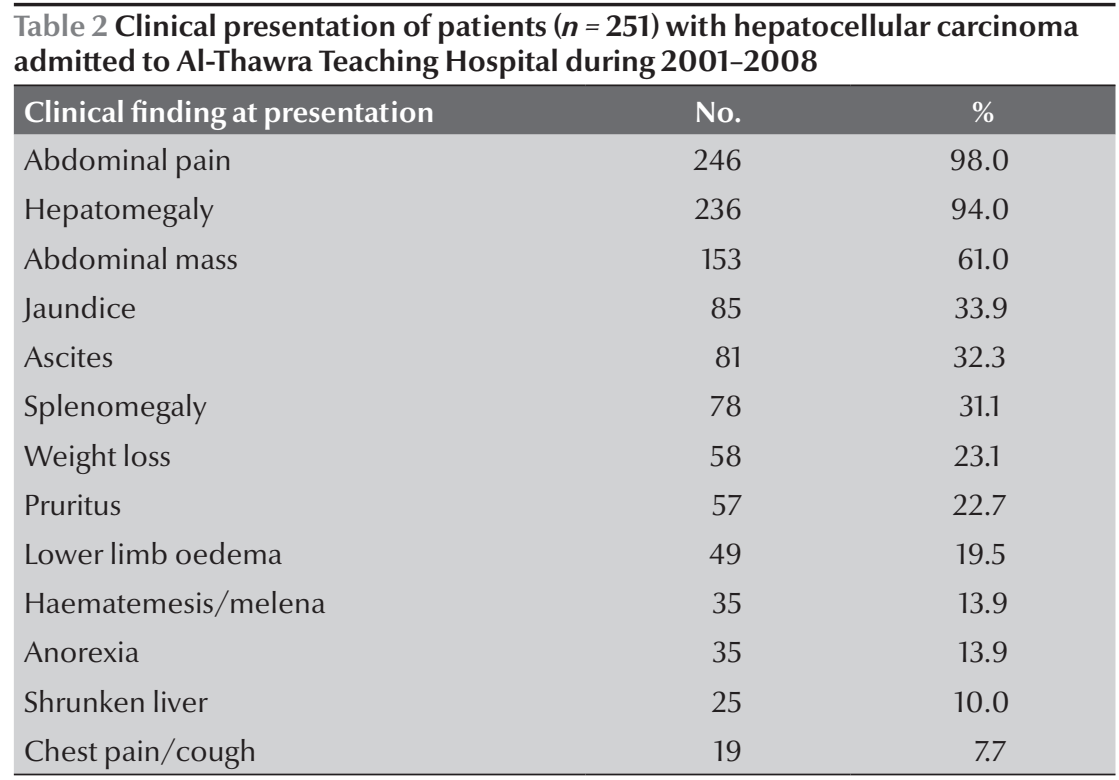

with cirrhosis, but the difference was not statistically significant $(P<0.05)$ (Table 4).

\section{Treatment and outcome of patients with HCC}

Tumour eligibility-for-treatment criteria in our hospital are: single nodule of $<5 \mathrm{~cm}$ without evidence of vascular invasion, or less than 3 nodules $<3 \mathrm{~cm}$ each with the absence of portal vein thrombosis.

Tumours $>5 \mathrm{~cm}$ in diameter were not considered eligible for any other curative treatment such as liver transplantation, percutaneous ethanol ablation, or radio frequency ablation. In any case, these types of therapy are not available in Yemen.

The majority of our patients with HCC 146 (58.2\%) were given chemotherapy in the form of doxorubicin and tamoxifen. Another68 (27.1\%) received supportive therapy only because of the advanced nature of the disease and general deteriorated condition. Surgery was

\begin{tabular}{|c|c|c|}
\hline Characteristic feature & No. & $\%$ \\
\hline \multicolumn{3}{|l|}{ Lesions } \\
\hline Unifocal (single) & 97 & 38.6 \\
\hline Multifocal (multiple) & 154 & 61.4 \\
\hline \multicolumn{3}{|l|}{ Site of lesion } \\
\hline Right lobe & 109 & 43.4 \\
\hline Left lobe & 67 & 26.7 \\
\hline Both & 75 & 29.9 \\
\hline \multicolumn{3}{|l|}{ Size of single lesion $(n=97)$} \\
\hline$<5.0 \mathrm{~cm}$ & 13 & 13.5 \\
\hline$\geq 5.0 \mathrm{~cm}$ & 84 & 86.5 \\
\hline \multicolumn{3}{|l|}{ Metastases $(n=164)$} \\
\hline Intra-abdominal & 72 & 74.0 \\
\hline Chest & 47 & 28.7 \\
\hline Lymph node & 45 & 27.4 \\
\hline Portal vein thrombosis & 32 & 12.7 \\
\hline
\end{tabular}

performed for 6 (2.4\%) patients (Table $5)$. We had no further information on treatment regime or outcome for the 31 (12.4\%) patients who were sent abroad for treatment. The overall mortality rate within 6 months of admission to hospital was $24.3 \%$. We were not able to follow up for more than 6 months. This was mainly due to the fact that the majority of patients lived in rural areas where there are no local medical facilities. Coming to our hospital for follow-up was difficult for them for financial reasons. Additionally, many of the patients are illiterate and they are not aware about the disease; they do not take the medical advice seriously and do not attend for follow-up.

\section{Discussion}

Worldwide, HCC is one of the most common malignancies associated with poor prognosis. [13]. The magnitude of the problem of HCC in Yemenis has not been explored yet. There has been a remarkable increase of the proportion of HCC among Yemenis over the last 8 years $[2,14]$ compared with the period before 2000, when HCC was rarely diagnosed [15]. Similar results have been reported from Egypt, Canada and the United States of America [16-18] .This rise in rates may be a result of the increasing risk factors such as the emergence of $\mathrm{HCV}$, the contribution of $\mathrm{HBV}$ infection, exposure of the population to carcinogens such as industrial chemicals and insecticides, pesticides and fertilizers, which are used in agriculture without any governmental control. Moreover, the improvement in the diagnostic tools for HCC will affect the rates and the increased survival rate among patients with cirrhosis may allow time for developing HCC [19].

In this study HCC was about 3 times more prevalent in men than in women: as has been shown consistently in other studies, incidence in males was considerably greater than for females; 


\begin{tabular}{|c|c|c|c|c|}
\hline Risk factor & All & With cirrhosis & Without cirrhosis & $P$-value \\
\hline & No. & No. & No. & \\
\hline \multicolumn{5}{|l|}{ Age (years) } \\
\hline$<60$ & 168 & 132 & 36 & \multirow[t]{2}{*}{0.045} \\
\hline$\geq 60$ & 83 & 55 & 28 & \\
\hline \multicolumn{5}{|l|}{ Sex } \\
\hline Male & 189 & 149 & 40 & \multirow[t]{2}{*}{0.007} \\
\hline Female & 62 & 38 & 24 & \\
\hline \multicolumn{5}{|l|}{$H B s A g$} \\
\hline Positive & 121 & 101 & 20 & \multirow[t]{2}{*}{0.002} \\
\hline Negative & 130 & 86 & 44 & \\
\hline \multicolumn{5}{|l|}{$H C V-A b$} \\
\hline Positive & 96 & 80 & 16 & \multirow[t]{2}{*}{0.015} \\
\hline Negative & 155 & 107 & 48 & \\
\hline \multicolumn{5}{|l|}{ Occupation } \\
\hline Farmer & 185 & 130 & 55 & \multirow[t]{2}{*}{0.01} \\
\hline Non farmer & 66 & 57 & 9 & \\
\hline \multicolumn{5}{|l|}{ Schistosoma } \\
\hline Positive & 91 & 72 & 19 & \multirow[t]{2}{*}{0.23} \\
\hline Negative & 160 & 115 & 45 & \\
\hline \multicolumn{5}{|l|}{ Qat chewer } \\
\hline Positive & 231 & 170 & 61 & \multirow[t]{2}{*}{0.30} \\
\hline Negative & 20 & 17 & 3 & \\
\hline \multicolumn{5}{|l|}{ Shama user } \\
\hline Positive & 88 & 62 & 26 & \multirow[t]{2}{*}{0.45} \\
\hline Negative & 163 & 125 & 38 & \\
\hline
\end{tabular}

$H B s A g=$ hepatitis B surface antigen; $H C V$ - $A b=$ hepatitis $C$ virus antibody.

this is obvious in cirrhotic patients with HCC. Worldwide however, the highest male:female ratio was in the Asian Pacific region, where chronic HBV infection is endemic [20]. In Japan men were at 4.35 times greater risk of developing HCC than women. The reasons for the disparity are obscure, but may include environmental factors such as a higher prevalence of persistent $\mathrm{HBV}$ or $\mathrm{HCV}$ infection, alcohol abuse, Qat chewing and smoking in men than in women [20]. Genetic and hormonal factors may also be important [21-23]. It has been speculated that estrogens and androgens could modulate hepatocarcinogenesis and explain the higher incidence of HCC in men [3].
The prevalence of HCC occurring in a younger age group compared to the western population [24] suggests an early exposure to carcinogenic factors in Yemeni patients.

This study presents a number of findings that are different from others that have previously addressed HCC in the Middle East region. We found that the Qat chewer and shama user had higher prevalence of HCC than other groups and hepatoma occurred in relatively younger patients. These 2 risk factors have not been addressed before and may have carcinogenic effects that enhance occurrence of HCC.

The most notable finding of this study, however, was that the majority of our patients presented with multiple liver focal lesions and mostly with right lobe involvement. Single focal lesions were $>5 \mathrm{~cm}$ in most patients. Portal vein thrombosis was present in $12.7 \%$ of cases: these findings indicate that the HCC patients in our study presented late, which may be a result of low level of awareness about HCC and its inherent dangers in the general population as a whole. The high poverty level in the population is another strong factor responsible for the late presentation as most would probably have visited the herbalists or religious homes (where treatment is based on religious faith) before ending up in the hospital. Valuable time would have been lost in the process. 


$\begin{aligned} & \text { Table } 5 \text { Treatment regimen and outcome for patients with hepatocellular carcinoma admitted to Al-Thawra Teaching Hospital } \\
& \text { during 2001-2008 }\end{aligned} \quad$ Total
\begin{tabular}{lcccc}
\hline Treatment & No. & $\%$ & Survived \\
& 146 & 58.1 & 118 & 80.8 \\
Chemotherapy & 68 & 27.1 & 42 & 61.7 \\
Supportive only & 31 & 12.4 & 25 & 80.6 \\
Sent abroad & 6 & 2.4 & 5 & 83.3 \\
Surgery & 251 & 100 & 190 & 75.7 \\
Total & & & No. \\
\hline
\end{tabular}

Other risk factors in this study which have significant role in developing HCC were older age and being a farmer. This is in concordance with the findings of other studies done in Egypt. [2,25] and Malaysia.[26]. It may be related to prolonged exposure to carcinogenic substances in the environment [25].

Histopathologically, the trabecular type was the most commonly encountered variety. This finding is similar to that noted by most other workers; the trabecular type being reported to be the most common type and constituting $60 \%-75 \%$ of HCC [24]

$\mathrm{HBV}$ is considered an important carcinogen via integration and promotion of random mutation [27]. The prevalence of $\mathrm{HBV}$ in our patients was $48.2 \%$. The prevalence of HBsAg carriers among the general Yemeni population varied from $12 \%$ to $20 \%$ [28]; these patients were at significantly risk of developing HCC. Case-control studies have demonstrated that chronic HBV carriers have a 5-fold increased risk of HCC compared with the general population [16]. The prevalence of HCV antibodies in our patients was $36.3 \%$. This etiological pattern is strikingly different from that of Europe and Egypt where $\mathrm{HCV}$ is the main cause of HCC. These differences may be related to the low prevalence of HCV infection among the general population in Yemen, range $2 \%-4 \%[27]$.

HCV has been shown to be implicated in the development of HCC in countries with intermediate or low incidence of HBsAg positivity [29]. The possible role of $\mathrm{HCV}$ in liver carcinogenesis is through cirrhosis. This is supported by the lack of reverse transcriptase in HCV and absence of integration of HCV genome into cellular genome [29]. Recently, a direct role has been noted for HCV in hepatocarcinogenesis: it is now believed that the core component of HCV may directly participate in hepatocarcinogenesis [27].

It was surprisingly that the proportion of patients with negative viral markers in this study is higher than in Egypt [2]. But is similar to that in the United States of America, where El-Serag reported that $14.5 \%$ of patients with HCC remain without specific risk factors and are diagnosed with nonspecific cirrhosis. This could be explained by the development of mutant or occult viral infections or exposure to other risk factors such as aflatoxins and heavy smoking. In addition to these, the Yemeni population is exposed to other risk factors which may lead to chronic liver disease such as schistosomiasis. This induces immune suppression, which could result in increased persistence viraemia following acute infection of both hepatitis $B$ and $C[30]$.

It is likely that $\mathrm{HCC}$ will continue to rise in the next few decades. Therefore, further studies to assess the magnitude and risk factors of HCC in Yemen and other developing countries seem warranted.

\section{Conclusion}

Both HBV and HCV are considered risk factors for HCC occurrence with the greater role of $\mathrm{HBV}$ in Yemeni patients.

Our study produced important preliminary insights that can be used to develop more refined, prospective analyses of HCC risk in Yemen.

\section{References}

1. Parkin DM et al. Global cancer statistics. CA a CancerJournal for Clinicians, 2005, 55:74-108.

2. El-Zayadi A et al. Hepatocellular carcinoma in Egypt: a single center study over a decade. World Journal of Gastroenterology, 2005, 11: 5193-5198.

3. Salem AK et al. Pattern of gastrointestinal tract malignancy at Al-Thawra Hospital. Sanaa University Journal of Medicine and Science, 2004, 1:37-43.
4. McGlynn K, London W. Epidemiology and natural history of hepatocellular carcinoma. Best Practice \& Research Clinical Gastroenterology, 2005:19:3-23.

5. Bassily $\mathrm{S}$ et al. Hepatitis $\mathrm{C}$ virus infection and hepatosplenic schistosomiasis. Scandinavian Journal of Infectious Diseases, 1992, 24:687-688.

6. Abdel-Hamid N. Update to risk factors for hepatocellular carcinoma. International Journal of Medicine and Medical Science, 2009, 1(3):38-43 
7. Levrero M. Viral hepatitis and liver cancer: the case of hepatitis C. Oncogene, 2006, 25:3834-3847.

8. Shobokshi $\mathrm{O}$ et al. The prevalence of hepatitis $\mathrm{C}$ virus in patients within established primary hepatocellular carcinoma in the Western region of Saudi Arabia. Saudi Medical Journal, 2003, 24(Suppl. 2):S130.

9. Akhtar SS and Reyes LM. Cancer in Al-Qassim, Saudi Arabia: a retrospective study (1987-1995). Annals of Saudi Medicine, 1997, 17(6):595-600.

10. Toukan A et al. The epidemiology and clinical outcome of hepatitis D virus (delta) infection in Jordan. Hepatology, 1987, 7:1340-1345.

11. Uzunalimoglu $\mathrm{O}$ et al. Risk factors for hepatocellular carcinoma in Turkey. Digestive Diseases and Sciences, 2001, 46:1022-1028.

12. Alacacioglu A et al. Epidemiology and survival of hepatocellular carcinoma in turkey: outcome of multicenter study. Japanese Journal of Clinical Oncology, 2008, 38(10):683-688.

13. Okano $\mathrm{H}$ et al. Treatment of hepatocellular carcinoma and the exacerbation of liver function. International Journal of Oncology, 2001, 19:1279-1282.

14. Al-Thobhani KA, Raja'a AY, Noman AT. The pattern and distribution of malignant neoplasms among Yemeni patients. Saudi Medical Journal, 2001, 22:910-913.

15. Aulaqi MS et al. Cancer in Yemen 1982 to 1992: analysis of 2750 cases in the north-western governorates of Yemen. Egyptian Journal of Surgery, 1999, 18:157-164.

16. El-Serag HB. Hepatocellular carcinoma: an epidemiologic view. Journal of Clinical Gastroenterology, 2002, 35(Suppl. 2):S72-S78.

17. Bruix J et al. EASL Panel of Experts on HCC. Clinical management of hepatocellular carcinoma. Conclusions of the Barcelona-2000 EASL Conference. Journal of Hepatology, 2001, 35:421-430.

18. Yu MC et al. Epidemiology of hepatocellular carcinoma. Canadian Journal of Gastroenterology, 2000, 14:703-709.
19. El-Serag HB. Epidemiology of hepatocellular carcinoma. Clinical Liver Disease, 2001, 5:87-107.

20. Wands J. Hepatocellular carcinoma and sex. New England Journal of Medicine, 2007, 357, 19:1974-1976.

21. Yu MW et al. Role of reproductive factors in hepatocellular carcinoma: impact on hepatitis B and C-related risk. Hepatology, 2003, 38:1393-1400.

22. Naugler WE et al. Gender disparity in liver cancer due to sex differences in MyD88-dependent IL-6 production. Science, 2007, 317:121-124.

23. Kasahara A et al. Risk factors for hepatocellular carcinoma and its incidence after interferon treatment in patients with chronic hepatitis C. Osaka Liver Disease Study Group. Hepatology, 1998, 27:1394-1402.

24. Nzeako UC, Goodman ZD, Ishak KG. Comparison of tumor pathology with duration of survival of North American patients with hepatocellular carcinoma. Cancer, 1995, 76:579-588.

25. Mohamad NH et al. Review of epidemiological and clinicopathologic features of 403 HCC patients. Journal of the Egyptian National Cancer Institute, 2000, 12:87-93.

26. Cheah PL et al. Histopathological landmarks of hepatocellular carcinoma in Malaysians. Malaysian Journal of Pathology, 2003, 25(1):37-43

27. Rahman El-Zayadi A et al. Prevalence and epidemiological features of hepatocellular carcinoma in Egypt-a single center experience. Hepatology Research, 2001, 19:170-179.

28. Scott DA et al. A seroepidemiological survey of viral hepatitis in the Yemen A.R. Transactions of the Royal Society of Tropical medicine and Hygiene, 1990, 84:288-291.

29. Paterlini $\mathrm{P}$ et al. Persistence of hepatitis B and hepatitis $\mathrm{C}$ viral genome in primary liver cancers from $\mathrm{HBsAg}$ negative patients. A study of low endemic area. Hepatology, 1993, 17:20-29.

30. Ghaffar YA et al. The impact of endemic schistosomiasis on acute viral hepatitis. American Journal of Tropical Medicine \& Hygiene, 1991, 45:743-750. 